\title{
Psychometric Properties of the Self-Care Inventory for Children with Cerebral Palsy in a Resource-Constrained Urban South African Context
}

\author{
Caroline Seward. BA Social Sciences (US); BOT (US); MSc OT (Wits). \\ http://orcid.org/0000-0002-8360-I 20 I \\ Practitioner at Dysart Special Needs School, Surbiton, England, United Kingdom. Postgraduate student, Department of Occupational \\ Therapy, School of Therapeutic Sciences, Faculty of Health Sciences, University of the Witwatersrand, Johannesburg, South Africa.
}

\author{
*Denise Franzsen. BSc OT (Wits), MSc OT (Wits), DHT (UP) PhD (Wits). \\ http://orcid.org/0000-000 I-8295-6329 \\ Sessional Senior Lecturer, Department of Occupational Therapy, School of Therapeutic Sciences, Faculty of Health Sciences, University of \\ the Witwatersrand, Johannesburg, South Africa.
}

Introduction: For children with cerebral palsy (CP), conducting self-care tasks may be difficult due to physical and cognitive problems. Accurate assessment of children with $C P$ is needed for realistic intervention. The Self-Care Inventory for Children with Cerebral Palsy (SCICP) was developed by Julia Burg in 2016. The SCICP is a caregiver reported questionnaire that aims to assess the extent to which a CP child can conduct their self-care tasks independently. Burg created the SCICP due to the lack of a valid assessment tool for the South African population to assess CP children's self-care abilities. The aim of the study was to investigate selected psychometric properties of the SCICP in terms of known-group validity, concurrent validity with the gross motor function, and manual abilities of the children with $C P$ as well as the tool's diagnostic accuracy.

Method: A quantitative cross-sectional, non-experimental study design with the caregivers of 50 children with CP ( 0 to 8-years-old), and 50 typically developing children (0 to 6-years-old) was conducted. Data were collected at two hospitals in the Ekurhuleni district in Gauteng, South Africa. The caregivers completed a demographic questionnaire and the SCICP assessment tool for each child. Descriptive statistics and non-parametric statistics including the Mann- Whitney $U$ test as well as Spearman's correlation co-efficient were used to analyse the data, since data were ordinal. Sensitivity and specificity and internal consistency were also established.

Results: The SCICP differentiates between children who are typically developing and children with CP who present with developmental delay on the overall score. For some components of self-care activities for the 0 to $I$-year-old children, the difference in scores is not significant since typically developing children of this age may be dependent in many self-care tasks.

Conclusion: The SCICP shows promising results for use in the clinical setting to identify deficits in CP children's ability to perform their self-care tasks and provide guidance for intervention for self-care for children with $C P$.

Keywords: Cerebral palsy; resource-constrained environment; self-care; participation; evaluation; known-group validity; functional mobility; low socio-economic status.

\section{INTRODUCTION AND BACKGROUND}

Cerebral palsy $(\mathrm{CP})$ is a disorder that is prevalent in developing countries and can negatively impact on a child's ability to perform their self-care tasks and increase the burden of care for caregivers'. In many African countries, even though there are concerns of an underreporting of $\mathrm{CP}$, the prevalence is still considered to be greater than the predicted 2-2.5 per 1000 live births that has been documented in developed nations ${ }^{2}$. In a study conducted by Couper ${ }^{3}$, the prevalence of $\mathrm{CP}$ in a rural community in KwaZulu-Natal was as many as 10 per 1000 live births ${ }^{4}$ which may be related to the significantly higher prevalence of children with intrapartum-related causes of CP, such as intrapartum hypoxia, compared to that in developed countries.

Children with CP often fall short of the typical developmental trajectory and, thus, experience barriers to participation in activities of daily living such as self-care. Due to limitations in gross motor ability, hand function, cognition and other associated impairments, children with $\mathrm{CP}$ are not able to complete these activities independently ${ }^{5}$. Systematic and correct monitoring and documentation of children's developmental progress can take place with appropriate assessment. This ensures that intervention planning is more specific. Literature has shown that this will lead to an improvement in the overall participation of children in their daily tasks and decrease the burden of care on caregivers ${ }^{1,6,7}$.

Burg $^{8}$ highlighted in 2016 that within current occupational therapy practice in South Africa, there were no contextually relevant assessment tools to assess the self-care tasks of children with CP living in resource-constrained areas. She developed the Self-Care Inventory for Children with Cerebral Palsy (SCICP), which considered the differences of the occupational form of how self-care activities are completed by children with CP living in low socio-economic contexts in South Africa. The SCICP was designed as a caregiver report questionnaire which focuses specifically on a child's level of independence in performing their self-care tasks ${ }^{8}$. During the initial piloting phase of the SCICP, results showed that the tool was compatible with local service delivery needs and was appropriate for use in the context for which it was developed. Alignment was also found between the assessment tool and the 
theoretical and empirical constructs considered. The tool also had good population fit. In terms of usability, the tool was lowcost. Administration of the SCICP was feasible in the context for which it was designed and made use of an interview or caregiver report format in the home language of the caregiver of the child with CP. Thus, the assessment tool was found to be acceptable to the stakeholders involved ${ }^{8,9}$. Burg suggested that further reliability and validity testing of the SCICP was needed in order for the tool to be used as a standardised assessment within clinical practice ${ }^{8}$. Other than content validity, the psychometric properties of the assessment had not been established and the technical adequacy of the assessment tool needed to be confirmed to ensure that it accurately identified individuals at risk of developmental delay in self-care in the target population.

In this study, the known-group validity of the SCICP was established by comparing a group of typically developing children to a group of children with CP of similar ages. The concurrent validity with the gross motor function and manual abilities of the children with CP as well as the sensitivity and specificity of the assessment tool were also determined. This established the ability of the SCICP to identify those at risk of dysfunction in self-care, the relationship of the self-care dysfunction assessed with the severity of the $C P$ and the diagnostic accuracy of the assessment tool.

\section{LITERATURE REVIEW}

Cerebral palsy is considered one of the most common causes of chronic disability and one of the most complex conditions which occurs in early childhood ${ }^{5,10-12}$. The variety of associated impairments found in children with CP can significantly limit their functional participation ". In a study conducted in Canada ${ }^{12}$, as well as in an Iranian study $^{10}$, participation in self-care was determined to be central to a child's development, health, and well-being. Participation in selfcare was also reported as one of the most important outcomes of rehabilitation intervention for young children with $C P$. The acquisition of self-care in children with CP has been linked to the classification systems used to identify the gross motor function and manual abilities of children with CP, namely the Gross Motor Function Classification System (GMFCS) and the Manual Ability Classification System (MACS). According to Paulson and Vargus-Adams ${ }^{14}$, these classifications are reliable and can be used cross culturally with children with varying MACS and GMFCS levels. However, participation in self-care is also dependent on a child's cognitive ability, the environment in which the activity is carried out, the assistance given and the amount of time spent performing the skill ${ }^{5}$.

Evaluation, or assessment, constitutes the initial step in the occupational therapy process and guides understanding the activity limitations and restrictions in participation in self-care. This evaluation needs to take place continuously throughout intervention to ensure specific outcomes are met. In a systematic review conducted by Donald et $a^{15}$ in twenty-two African countries, health care professionals highlighted the need for early identification and evaluation of children with $\mathrm{CP}$ to facilitate the early provision of intervention for these children ${ }^{15}$. This is important since in under-resourced countries, there is a greater prevalence of children born with $C P$ and often the extent of their disability is more severe ${ }^{16}$. These children also experience greater barriers to accessing health care services $^{15,17}$. It is, therefore, important that there is availability of appropriate standardised assessment tools for use with these children to ensure appropriate management in terms of rehabilitation.

The standardised self-care assessment tools available, however, are not specific to children with CP in South Africa living in resource- constrained areas. In this context, self-care activities are carried out according to limited access to water, electricity, sanitation facilities and space ${ }^{18}$. Due to the complex interaction that poverty and the limited access to resources have on the management of CP children, a need for quick, convenient and cost-effective assessment to identify children who require intervention for self-care skills, was identified ${ }^{8}$. Burg ${ }^{8}$ developed an assessment tool to address this need and enhance independence in the self-care abilities of children with $\mathrm{CP}$ living in resource-constrained areas.

A review of existing standardised assessment tools that measure self-care in children with and without disabilities led to the creation of the SCICP. Test items based on this review were then analysed and underwent test definition, construction, item preparation, planning and revision. Finally, content validity of the assessment tool was established from both a subject matter expert and end user perspective. Items on the SCICP were presented sequentially according to typical developmental milestones that are achieved in each area of self-care ${ }^{8}$.

The initial field testing highlighted that the SCICP was able to determine the extent to which a child can perform their self-care tasks as well as determine a difference in test scores between typically developing children and children with $\mathrm{CP}$ of similar ages. However, due to the small sample used by $\mathrm{Burg}^{8}$, inferences based on the performance of typical or $\mathrm{CP}$ children on the SCICP was not determined. A guide for interpretation of the scores can only be conducted once the SCICP assessment has proven reliability and validity on a larger population. Thus, further validity testing of the SCICP was necessary before it can confidently be used in the clinical setting.

This study, therefore, determined the adequacy of the knowngroup validity, components of content validity, internal consistency, and diagnostic accuracy of the SCICP for children with CP living in a resource-constrained context in South Africa.

\section{METHODS}

\section{Research design}

The research design for this study was a descriptive quantitative, cross-sectional study design. This non-experimental design was used to determine the known-group validity, concurrent validity with the gross motor function and manual abilities of the $\mathrm{CP}$ children as well as the sensitivity and specificity of the assessment to determine the tool's overall diagnostic accuracy.

\section{Research site, population and sample}

Data were collected at two hospitals in the Ekurhuleni district in Gauteng. The hospitals are the largest hospitals in the Ekurhuleni Metropolitan Municipality and many people access health care services provided by these two hospitals from nine surrounding areas: Germiston, Alberton, Benoni, Boksburg, Brakpan, Kempton Park or Tembisa, Edenvale, Daveyton, Nigel and Springs ${ }^{19}$.

Caregivers of children with CP (6 months - 8 years, 6 months) who attend the CP clinic at the two hospital sites, which is an outpatient service run by the multidisciplinary team (MDT), were recruited. Children had a confirmed diagnosis of $C P$ by a doctor at the hospital with various levels of severity, based on the GMFCS and MACS classifications. These levels were confirmed by an experienced occupational therapist or physiotherapist.

The caregivers of typically developing children (6 months -6 years, 6 months) who attended appointments at the paediatric outpatient department at one hospital were recruited. The child's developmental status was confirmed in their hospital file, and it 
was established that they were attending routine check-ups for immunization or minor illness.

Most of the caregivers and their children lived in informal settlements in the Ekurhuleni district and were selected for the study as they were from areas with low socio-economic status and spoke either isiZulu or Sesotho.

Based on the greatest number of items (25) in the dressing domain in the SCICP according to $90 \%$ of studies reviewed, a participant item ratio of 2 for newly developed client reported outcomes measures was required ${ }^{20}$. Therefore, a sample of 50 caregivers with typically developing children and a sample of 50 caregivers of children with $\mathrm{CP}$ was required.

\section{Measurement instruments}

The researcher developed the demographic questionnaire, and it was conducted as a self-report questionnaire with all caregivers. Questions included information regarding the child's demographics including medical information, birth, and developmental history. Caregivers were also asked to indicate factors related to resources available to the family, social grants received and the employment status of family members. For the children with $\mathrm{CP}$, additional information regarding the child's GMFCS level and MACS levels was included by the researcher and research assistants. This information was obtained from the children's hospital files through an assessment that was conducted by an experienced occupational therapist and physiotherapist. Further information regarding any associated impairments was also taken from the child's hospital file.

\section{Self-Care Inventory for Children with Cerebral Palsy}

The SCICP is a caregiver report questionnaire that caregivers completed to indicate the extent to which their children could perform their self-care activities independently. The self-care domains as well as the number of test items included in each domain are as follows: eating (19), functional mobility associated with eating ( 10$)$, dressing (23), functional mobility associated with dressing (2), washing ( 10$)$, functional mobility associated with washing (8), grooming (9), functional mobility associated with grooming (2), toileting (5), functional mobility associated with toileting (9), mobility related to sleep (3) and general mobility (9). The format required the respondents to tick the responses in blocks on a scale of one to four. The SCICP provides items, which assess typically developing children's self-care abilities up to the age of 6 years, 6 months. This is typically the age at which most self-care skills have been reached developmentally. The SCICP can be used to assess children with CP that are older due to delays in achieving self-care developmental milestones.

Scoring was based on the caregivers' answers that indicated if the child could perform the self-care activity independently (4), with a little assistance (3), with a lot of assistance (2), or not at all (I). The assessment form was provided in English, isiZulu and Sesotho (translated from the original English). In cases where caregivers required assistance, the information could be gathered by means of interviews. The older the typically developing child is, the higher the score the child is expected to achieve for the test items in each test domain as well as a higher overall score. Younger typically developing children will achieve lower scores per test domain as well as in their overall scores. This is because developmentally, they are not yet able to reach certain milestones in completing self-care tasks independently.

\section{Research procedure}

After an initial pilot of the demographic questionnaire and SCICP with a caregiver of a typically developing child was conducted, the research assistant as well as the Grade I occupational therapist at the second hospital were trained in how to administer both the demographic questionnaire as well as the SCICP before data collection began. If the caregivers of typically developing children agreed to participate in the study, the child's file was checked with the caregiver's permission to exclude any children that did not meet the inclusion criteria. Data were collected by caregivers completing the demographic questionnaire and the SCICP for their child either independently or with verbal assistance from the researcher, the occupational therapist at the other hospital or the research assistant. The researcher scored all the completed assessments.

\section{Ethical considerations}

Ethical clearance for this study was obtained from the University of Witwatersrand's Human Research Ethics Committee (MI80954). Permission from the chief executive officers (CEOs), the head of paediatrics and the head of the Occupational Therapy Departments were obtained. All caregivers recruited into the study were provided with an information sheet regarding the study and signed informed consent before completing the demographic questionnaire and the SCICP. All documents were made available in English, isiZulu and Sesotho. If caregivers' literacy levels were low, the information sheet and informed consent form was verbally communicated to them in their home language. Furthermore, caregivers were informed that participation in the study was voluntary and that they could refuse to participate or withdraw their participation at any stage of the research process without any consequence or effect on treatment or therapy received by their child. No identifying information of the children was used during data capturing or during the data analysis phases of the research process.

\section{Data analysis}

The demographic information was presented in the form of descriptive statistics including frequencies and percentages. Data were analysed using TIBCO Statistica $v$ 13.2. Due to the ordinal data and the small sample within each age group for the typically developing children and children with $\mathrm{CP}$, non-parametric statistics were used. The known-group validity of the Fischer's exact test was used to compare the median scores of the typically developing children to the median scores of the children with CP. This was done for each age group.

Concurrent validity for the SCICP and the GMFCS and MACS level scores was established using Spearman's correlation coefficient. Sensitivity and specificity statistics were calculated to establish the positive and negative likelihood ratios and accuracy statistics for the SCICP to identify how accurately the SCICP identifies developmental delay in children with CP in terms of their self-care abilities.

\section{RESULTS}

\section{Demographics}

Demographic information was collected for the CP and typically developing children. The total sample of children consisted of 56 males and 49 female participants. In total, there were 54 children with CP (55\% male and $45 \%$ female) and a total of $5 \mathrm{I}$ typically developing participants (51\% male and $49 \%$ female).

The birth history of the children indicated that the mode of birth and gestation period did not differ significantly between the group of typically developing children and those with CP. More than two thirds were vaginal deliveries and over half of the children were delivered at 38-40 weeks gestation. 
Table I: Gross Motor Function Classification System (GMFCS) level and Manual Abilities Classification System (MACS) level for children with cerebral palsy.

\begin{tabular}{|l|l|l|}
\hline & \multicolumn{1}{|l|}{ GMFCS level } & MACS level \\
\hline Level & $\mathrm{n}(\%)$ & $3(5.6)$ \\
\hline I & $4(7.4)$ & $4(7.4)$ \\
\hline II & $5(9.3)$ & $10(18.5)$ \\
\hline III & $3(5.6)$ & $8(14.8)$ \\
\hline IV & $18(33.3)$ & $22(40.7)$ \\
\hline V & $18(33.3)$ & $7(13)$ \\
\hline Missing & $6(11.1)$ & \\
\hline
\end{tabular}

Table II: Socio-economic indicators provided by caregivers of children with CP and typically developing children.

\begin{tabular}{|c|c|c|c|}
\hline & Category & $\begin{array}{l}\text { Caregivers of } \\
\text { children with } \\
\text { cerebral palsy }\end{array}$ & $\begin{array}{l}\text { Caregivers } \\
\text { of typical } \\
\text { children }\end{array}$ \\
\hline & & n (\%) & \\
\hline \multirow{3}{*}{$\begin{array}{l}\text { Employment } \\
\text { status of } \\
\text { caregivers }\end{array}$} & Employed & $25(46.3)$ & $15(29.4)$ \\
\hline & Unemployed & $26(48.1)$ & $35(68.6)$ \\
\hline & Missing & $3(5.6)$ & I (2) \\
\hline \multirow{3}{*}{$\begin{array}{l}\text { Access to } \\
\text { water and } \\
\text { electricity }\end{array}$} & Yes & $47(87)$ & $46(90.2)$ \\
\hline & No & $5(9.3)$ & $3(5.9)$ \\
\hline & Missing & $2(3.7)$ & $2(3.9)$ \\
\hline \multirow{4}{*}{$\begin{array}{l}\text { Grants } \\
\text { received }\end{array}$} & Childcare grant & $2(3.7)$ & $32(62.7)$ \\
\hline & $\begin{array}{l}\text { Child } \\
\text { dependency } \\
\text { grant }\end{array}$ & $34(62.9)$ & 0 \\
\hline & Not specified & $6(11.1)$ & $5(9.8)$ \\
\hline & $\begin{array}{l}\text { Nor receiving } \\
\text { grant }\end{array}$ & $12(22.2)$ & I4 (27.5) \\
\hline
\end{tabular}

The children with $\mathrm{CP}$ were classified according to different types of CP. The most common type of CP among the sample was spastic quadriplegia $(n=19 ; 35 \%)$ and spastic quadriplegia with elements of dystonia $(n=12 ; 22 \%)$. Two thirds of the children with CP were classified on GMFCS level IV and level V. This indicates severe limitations in mobility, with children being wheelchair or buggy bound and unable to move by themselves. More than half of this sample also presented on MACS level IV and level $\mathrm{V}$ indicating severe difficulty with hand function and handling objects (Table I adjacent).

The children with $\mathrm{CP}$ also presented with a number of associated impairments. Nineteen (35\%) of the CP children had confirmed visual impairment, four (7\%) children with $\mathrm{CP}$ had been diagnosed with hearing impairment, and four children required percutaneous endoscopic gastrostomy (PEG) feeding. The children who required PEG feeding are fully dependent and scored a one for all eating test items ( 19 items) and functional mobility associated with eating items ( 10 items). Of the 54 children in the sample, 24 (44\%) children had a confirmed diagnosis of epilepsy.

\section{Socio-economic indicators}

All the children and their caregivers came from low socio-economic backgrounds. Less than half ( $46 \%$ ) of the caregivers of children with $\mathrm{CP}$ and $29 \%$ of the caregivers of typically developing children, were employed. A third of the caregivers for both groups reported that no one in their household was employed. The majority of the caregivers of the children with $\mathrm{CP}$ and the typical population relied on social grants for their children to supplement their personal income. The availability of water and electricity status varied among participants. Although the majority of participants had access to water and electricity, they could not always afford to use electricity since 93\% of caregivers lived in informal settlements (Table II adjucent).

\section{Known-group validity of the Self-Care Inventory for Children with Cerebral Palsy}

The scores for the typical children and the children with CP were $\mathrm{n}$ with $\mathrm{CP}$ in the 7 and 8 ared to the typical 6-year-

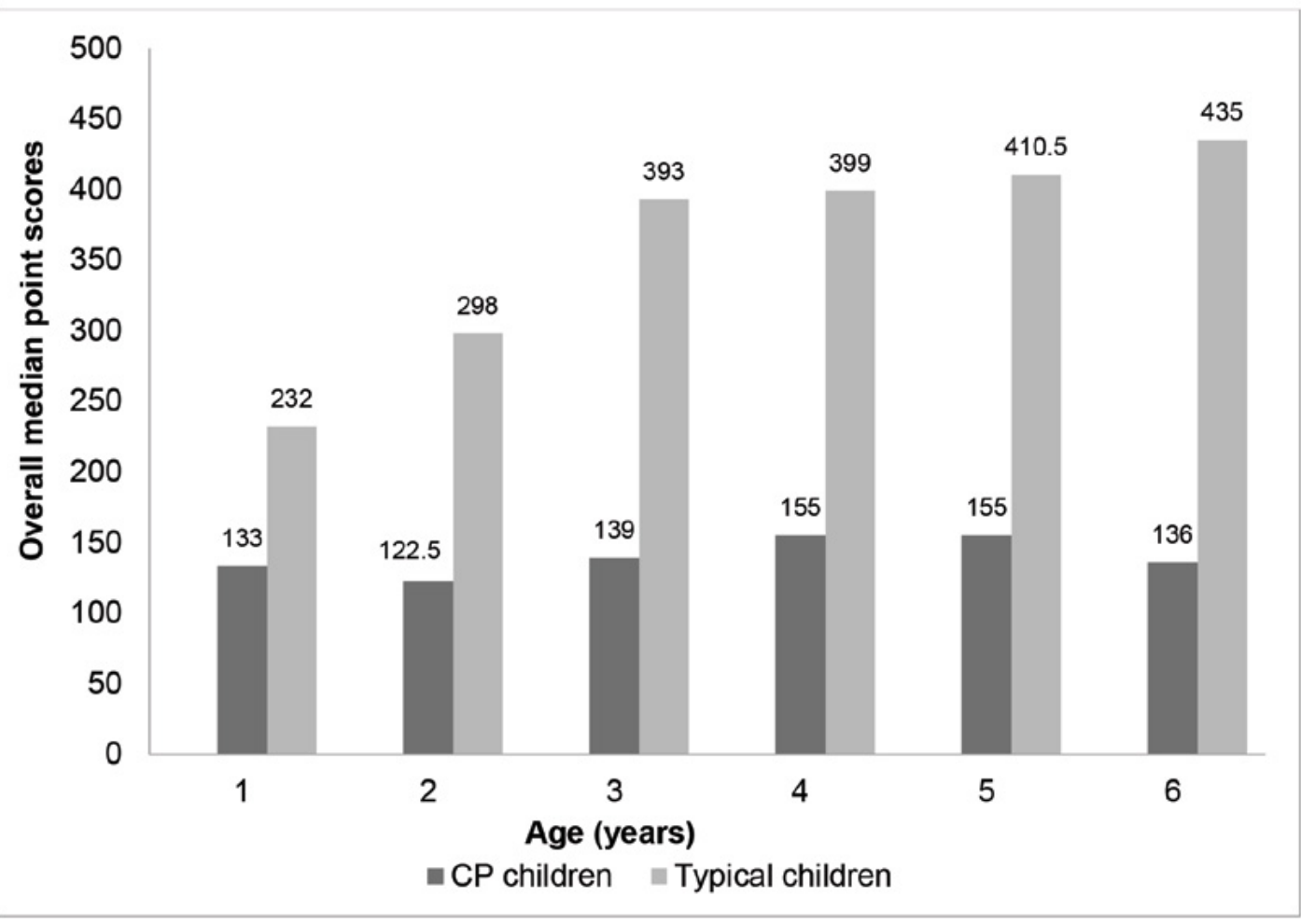

Figure I: Overall median point scores comparing children with cerebral palsy and typical children ages I to 6-years-old. 


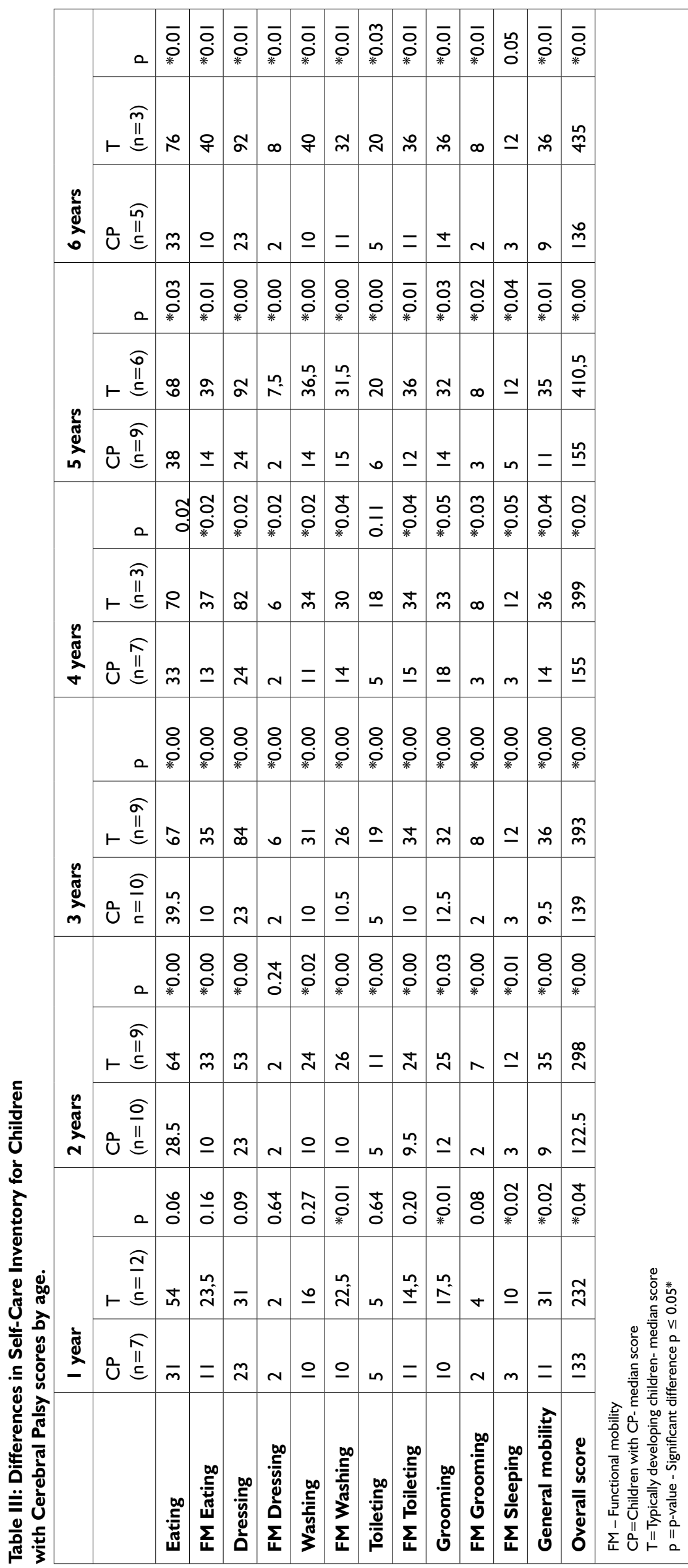

dren. Figure I and Table III depict the difference in overall median point scores and the overall confidence interval scores for the children with $\mathrm{CP}$ and typical children on the SCICP.

For the typical children, one can see that for each domain, the scores of the children increases steadily as the child increases in age.

The scores for the $\mathrm{CP}$ children showed that for every domain for each age group, the scores were lower than that of the typical sample of children. As the typically developing children increase in age, the difference in scores becomes greater between the children with $\mathrm{CP}$ and the typical children. The Fischer's exact test was used in order to determine if there was a significant difference between the two sample groups, thereby confirming known-group validity of the research tool ${ }^{21}$. A statistically significant difference was found between the two groups for the majority of the scores across all the domains and age groups. When comparing the scores for the I-year-old groups of typical children and children with CP, most of the test domains were not statistically significantly different. It is interesting to note, however, that the overall point score for this age group still showed a significant difference $(p=0,04)$ (Table III p29).

\section{Concurrent validity of the Self-Care In- ventory for Children with Cerebral Palsy to the severity of cerebral palsy}

When the relationship between the SCICP scores for children with $\mathrm{CP}$ and the severity of their CP assessed by their GMFCS and MACS levels were compared, a negative correlation was observed (Table IV pxx). As the GMFCS and MACS level increases (higher levels indicate greater restrictions in gross motor and hand function ability), the children's scores decreased (indicating a poorer performance in self-care participation and independence). A strong to moderate correlation was observed when comparing the scores of children with $\mathrm{CP}$ with their GMFCS levels $(r=-0.46$ to -0.78$)$. All correlations were statistically significant. Although the CP children's MACS level scores were also significantly correlated, these correlations were weak to moderate $(r=-0.36$ to -0.65$)$.

The diagnostic accuracy in terms of sensitivity and specificity of the Self-Care Inventory for Children with Cerebral Palsy Sensitivity and specificity are measures of knowngroup validity. They can be used to determine the ability of the SCICP to correctly identify children with deficits (true positive rate), or correctly identify children without deficits (true negative rate) $)^{22}$. The overall score of the children with $\mathrm{CP}$ shows that when compared to the lower band of the $95 \%$ confidence interval of the overall score of the typical children, the SCICP had $87.5 \%$ 
Table IV: Age, Gross Motor Function Classification System (GMFCS) level and Manual Abilities Classification System (MACS) level correlations for children with cerebral palsy.

\begin{tabular}{|c|c|c|c|}
\hline & Age (years) & GMFCS level & MACS level \\
\hline $\begin{array}{l}\text { Domains of } \\
\text { SCICP }\end{array}$ & \multicolumn{3}{|l|}{ rho } \\
\hline Eating & $0.28^{*}$ & $-0.69 *$ & $-0.49 *$ \\
\hline FM Eating & 0.24 & $-0.7 I *$ & $-0.65 *$ \\
\hline Dressing & 0.23 & $-0.62 *$ & $-0.5 I^{*}$ \\
\hline FM Dressing & $0.28 *$ & $-0.46 *$ & $-0.36 *$ \\
\hline Washing & 0.27 & $-0.68 *$ & $-0.55 *$ \\
\hline FM Washing & 0.26 & $-0.72 *$ & $-0.52 *$ \\
\hline Toileting & $0.39 *$ & $-0.57 *$ & $-0.45 *$ \\
\hline FM Toileting & 0.27 & $-0.65 *$ & $-0.5 I^{*}$ \\
\hline Grooming & $0.44 *$ & $-0.65 *$ & $-0.50 *$ \\
\hline FM Grooming & $0.37 *$ & $-0.78 *$ & $-0.46 *$ \\
\hline FM Sleeping & $0.28 *$ & $-0.78 *$ & $-0.57^{*}$ \\
\hline General mobility & 0.2 & $-0.73 *$ & $-0.64 *$ \\
\hline Overall score & $0.35^{*}$ & $-0.73 *$ & $-0.56 *$ \\
\hline \multicolumn{4}{|l|}{$\mathrm{FM}=$ Functional mobility } \\
\hline
\end{tabular}

sensitivity and $74.4 \%$ specificity. The positive likelihood ratio for the overall score was 3.4 and the negative likelihood ratio was 0.2 . The SCICP is $80.9 \%$ accurate in identifying self-care deficits in children with CP. This was affected by the results for children in the I-year-old age band who were identified as dependent, which should be considered normal at this stage of their development. Therefore, the scoring of these age bands may need to be adjusted as accuracy scores are at $69 \%$ for this age group (Table $\mathrm{Vp} 3 \mathrm{I}$ ).

\section{DISCUSSION}

The aim of the study was to investigate selected psychometric properties of the SCICP in terms of known-group validity, further content validity, internal consistency, and diagnostic accuracy for the assessment of children with CP living in a resource-constrained context in South Africa. The current study was completed on caregivers and children from low socio-economic status homes and limited resources in terms of amenities. South Africa is considered to be a low to middle income country (LMIC) with a large portion of the population living in moderate to extreme poverty ${ }^{23}$. Globally, $85 \%$ of children with a disability live in LMICs with their disability exacerbated by poverty and only $5 \%$ have access to rehabilitation ${ }^{24}$. Over $90 \%$ of the caregivers and their children in this study live in informal settlements, which consist predominantly of temporary structures built from basic materials. They lack adequate sanitation, quality water supply, and adequate living space. The limited living space, often confined to one room, functions as a place for multiple activities such as sleeping, cooking, and washing.

The occupational form, or way in which self-care activities are conducted, may be different to how these activities would be conducted in a home with many rooms including a kitchen and a bathroom. Water access is generally to a tap located outside of the house. Thus, the self-care task of washing includes collecting and boiling water for bathing. Washing subsequently takes place in a bucket inside the house. Eating does not always occur at a table and children may sleep on the floor instead of a bed ${ }^{25}$. Sanitation consists of ablution blocks and chemical toilets set up between the houses $^{26}$. Thus, the living conditions of the children affects how they perform their self-care tasks. The majority of informal settlements in the Ekurhuleni district are not situated on suitable land for housing making moving around in the community difficult as there are no formal roads and the terrain is often rough and muddy ${ }^{19}$.

Many of the caregivers are dependent on social grants due to high levels of unemployment and the cost associated with caring for a child, especially a disabled child. Most unemployed caregivers received a care dependency grant for their child with $\mathrm{CP}$, while those with typical children received a child support grant. However, as reported by Gutura and Tanga ${ }^{27}$, in a study completed in the community of Ngqushwa municipality in the Eastern Cape, the social grant money received is often insufficient to care for a child. This is especially true if they need to access health care and rehabilitation services regularly ${ }^{27}$.

When the known-group validity was considered, all scores for the children with $\mathrm{CP}$ were statistically lower than those of the typically developing children. Scores on the SCICP for the I-year-old group of typical children and children with CP, however, did not display as significant differences. This finding is in keeping with literature, indicating that limited independence is found in all children under the age of one year ${ }^{28}$. The differences in scores were significant as the typical children increased in age; gradual independence is achieved in self-care activities, as there is accelerated development of gross and fine motor skills and hand function. From the age of two years, independence in self-care tasks is enhanced over time due to increased opportunities to practice and develop these skills ${ }^{29}$.

When the minimum and maximum scores and $95 \%$ confidence interval scores were considered, limited ceiling and floor effects were found. None of the median scores for any domains reflected zero, this indicated that children with very low ability could still be assessed on the SCICP. Ceiling scores were achieved by typical children of 6-years-old for the domains of functional mobility associated with grooming. Sleeping and general functional mobility achieved ceiling scores by two to three years old. However, except for functional mobility associated with sleeping, the children with $\mathrm{CP}$ achieved none of these ceiling scores since motor function and mobility is one of the main deficits associated with CP.

The concurrent validity of the SCICP scores of the children with $\mathrm{CP}$ in the current study to the severity of their CP had a negative moderate to strong correlation with their GMFCS levels. These findings support those found by Kim et $a l^{29}$. and Parkes et $a^{30}$. who found a significant relationship between GMFCS levels and selfcare functional mobility. They found that the mobility score on the PEDI was the only significant factor influencing self-care ability in children with $\mathrm{CP}^{29,30}$. As in the current study, this included mobility in performance of the self-care task related to what an individual actually does in their environment on a daily basis. This includes their gross motor capacity related to performance of the task in a specific environment. In the SCICP, for example, this includes washing in a basin and bowl, using a toilet situated outside of the house and, thus, outdoor mobility. Outdoor mobility, however, did not include the use of stairs.

Unlike the PEDI, which has two separate sections for self-care and mobility, the SCICP includes functional mobility items related to each self-care domain. Each domain, for example, eating, has a functional mobility component associated with that task. Using the example of eating, functional mobility associated with eating includes activities such as fetching and carrying food. This supports the strong correlations found in the current study for these functional mobility 
Table V: Sensitivity and specificity of the Self-Care Inventory for Children with Cerebral Palsy.

\begin{tabular}{|c|c|c|c|c|c|c|}
\hline$(n=105)$ & & $\begin{array}{l}\text { Sensitivity } \\
\%\end{array}$ & $\begin{array}{l}\text { Specificity } \\
\%\end{array}$ & $\begin{array}{l}\text { Positive } \\
\text { Likelihood } \\
\text { Ratio }\end{array}$ & $\begin{array}{l}\text { Negative } \\
\text { Likelihood } \\
\text { Ratio }\end{array}$ & Accuracy \\
\hline & & \multicolumn{2}{|l|}{$\%$} & & & $\%$ \\
\hline \multirow{2}{*}{ Overall } & & 87.5 & 74.4 & 3.4 & 0.2 & 80.9 \\
\hline & $95 \% \mathrm{Cl}$ & $74.1-94.8$ & $58.5-85.9$ & $2.0-5.8$ & $0.1-0.4$ & $71.3-88.4$ \\
\hline \multirow{2}{*}{ I-year-olds } & & 71.4 & 66.7 & 2.1 & 0.4 & 69.1 \\
\hline & $95 \% \mathrm{Cl}$ & $30.2-94.8$ & $35.4-88.7$ & $0.8-5.4$ & $0.1-1.5$ & $44.0-87.5$ \\
\hline \multirow[b]{2}{*}{ 2-year-olds } & & 90 & 66.7 & 2.7 & 0.15 & 78.3 \\
\hline & $95 \% \mathrm{Cl}$ & $54.1-99.4$ & $30.9-90.9$ & $1.0-6.9$ & $0.0-1.1$ & $53.7-93.6$ \\
\hline \multirow{2}{*}{ 3-year-olds } & & 90 & 77.8 & 4.1 & 0.1 & 83.9 \\
\hline & $95 \% \mathrm{Cl}$ & $54.1-99.4$ & $40.1-96.1$ & $1.2-13.9$ & $0.0-0.9$ & $60.0-96.4$ \\
\hline \multirow{2}{*}{ 4-year-olds } & & 85.7 & 100 & Infinity & 0.1 & 92.8 \\
\hline & $95 \% \mathrm{Cl}$ & $42.0-99.2$ & $30.9-100$ & & $0.0-0.9$ & $59.0-99.9$ \\
\hline \multirow[b]{2}{*}{ 5-year-olds } & & 88.9 & 71.4 & 3.1 & 0.2 & 80.2 \\
\hline & $95 \% \mathrm{Cl}$ & $50.7-99.4$ & $30.2-94.9$ & $0.9-10.3$ & $0.0-1.1$ & $53.1-95.4-$ \\
\hline \multirow[b]{2}{*}{ 6-year-olds } & & 100 & 100 & Infinity & 0 & 100 \\
\hline & $95 \% \mathrm{Cl}$ & $46.3-100$ & $30.9-100$ & & & $63.1-100.0$ \\
\hline
\end{tabular}

sections on the SCICP when correlated to GMFCS and MACS levels. The MACS levels also showed weak to moderate correlations since the functional mobility items for each self-care domain, especially eating, washing and general mobility; include aspects that require hand function. A number of these items such as 'carries plate of food to the table', 'opens juice bottle', 'uses soap and cloth', 'carries objects large enough to require two hands' require hand function, which is also associated with independence in self-care ${ }^{31}$.

The diagnostic accuracy of the SCICP can be considered clinically relevant since both children with and without $C P$ were assessed. The SCICP showed high levels of sensitivity and specificity overall with an $80 \%$ accuracy level in identifying self-care deficits and developmental delay in children with CP correctly and not classifying typically developing children with self-care deficits ${ }^{32}$. The sensitivity score in identifying deficits and developmental delay is similar to the score reported for the WeeFIM on children with $\mathrm{CP}$ at $86,6 \%$ but the specificity is lower than the $82.2 \%$ reported by Bagley ${ }^{33}$.

For each age group, significant positive and negative likelihood ratios were below and above a score of one indicating the tool is clinically useful at identifying deficits and developmental delay in a population of children with CP. The level of sensitivity and specificity, however, reflects the dependence in self-care of younger children, which was not accommodated for by the SCICP.

\section{LIMITATIONS OF THE STUDY}

The length of the questionnaire and possible low levels of literacy may have affected the caregivers' understanding of the assessment. This meant that the researcher, occupational therapist at the second site of data collection and the research assistant, needed to be present for a greater portion of time whilst the assessment was administered.

The scores for the I-year-old groups of typical and CP children did not show statistically significant differences for the majority of the test domains on the SCICP. This means that the SCICP does not provide adequate evidence of delay in self-care for the I-year-old age group. The implication of this is that testing of children with suspected developmental delay is best performed from 2-years-old and up.

There is a lack of stratification in terms of age groups of the sample. This resulted in small sample groups, especially for the 4 year olds, which affected the results and normative medians for this age group. This may have resulted in a type II error whereby significant correlations may have been missed.

The small sample size for both the typical and CP children in different age groups means that these results cannot be extrapolated to the whole population. However, it does provide a starting point for normative data. The findings from the median scores of the typical children can be used to compare CP children's scores of similar ages.

\section{CLINICAL IMPLICATIONS}

Overall median scores from the typical children's results may be used as a guide for measuring children with CP's performance on the SCICP using their overall score on the SCICP. CP children with suspected developmental delay should only be assessed using the SCICP from 2 years up to 8 years of age. It is recommended that the SCICP be used in conjunction with functional classification systems, particularly the GMFCS and MACS. The SCICP should also be used in conjunction with other physical and cognitive assessments to provide a holistic understanding of the overall functioning of the child.

The assessing therapist may need to administer the SCICP as a semi-structured interview rather than a caregiver report questionnaire. It is recommended that the assessing therapist observe at least one self-care task of each test domain to ensure that the caregiver's report of their child's self-care participation is accurate. The assessing therapist will need approximately 45 minutes to one hour to administer the SCICP per caregiver and child. As the $\mathrm{SCICP}$ is long, it is suggested this assessment may be divided into sections and administered over two or three sessions, if necessary. Consideration may need to be given to making the SCICP a less detailed assessment. The assessment should be conducted on an individual basis. However, in a public health care setting, there might be scope for group administration of the test provided the assessing therapist has a co-assessor to assist with administration of the test.

Once all assessments have been conducted, a feedback session can be held with the caregiver(s) to discuss the factors influencing the CP child's self-care performance. Thereafter, collaborative goal setting with the caregiver, and if possible, the child, should be done. Improvements in the child's self-care functioning can be measured and recorded by administering the SCICP in the future.

As suggested in the study by Davies et $a^{34}$, the assessment form should be given to caregivers to go through a few days prior to completing the assessment, if possible. In this way, caregivers will 
be familiar with items on the test and can more accurately observe their child's performance in each activity domain before completing the questionnaire with the therapist ${ }^{34}$.

With regards to future research, the use of pictures in conjunction with a written description of the test item could be provided rather than only written descriptions of the test items should be considered. This would allow caregivers to easily see what skill is being assessed and how it is being done. The SCICP needs to be evaluated in the clinical setting to determine the responsiveness to changes in performance of self-care activities after intervention.

\section{CONCLUSION}

Since many assessment tools used for the South African population are based on assessment tools designed for use in developed countries, Burg developed the SCICP to enhance cultural and contextual appropriateness of test items. The goal of the development of the SCICP was to ultimately determine the extent to which children with $\mathrm{CP}$ living in resource-constrained areas can complete their self-care tasks. Many authors state that accurate assessment is needed for appropriate intervention ${ }^{8,16,35}$.

The results from the study showed the scores of the typically developing children increased steadily with an increase in age within each domain of self-care on the SCICP, including their overall point score. A significant difference was found between these scores and those achieved by most of the CP children, with the exception of the I-year-old group of children. This confirmed the difference between the two groups and the known-group validity of the SCICP. The concurrent validity of the SCICP for children with $\mathrm{CP}$ was found to have a significant negative correlation with regards to increased levels on the GMFCS and MACS.

Sensitivity and specificity of the test scores were found to be acceptable for the overall, as well as for each age group, score with the exception of the I-year- old age group.

The SCICP has shown promising results concerning the aspects of reliability and validity studied within this research report. It shows good potential for clinical use as a standardized tool within the South African context for a low socio-economic population of children with CP between the ages of 2 to 8 years of age.

\section{CONFLICTS OF INTEREST}

The project was funded by an Endowment Grant from the Faculty of Health Sciences, University of Witwatersrand

\section{AUTHOR CONTRIBUTIONS}

Caroline Seward conceptualised and completed research for project as a postgraduate student. Denise Franzsen supervised the project and both authors conceptualised and edited of the article.

\section{ACKNOWLEDGEMENTS}

The researchers wish to acknowledge the caregivers of the children with cerebral palsy with and Patricia (Tumi) Matlou and her daughter, Kgomotso. Their commitment to the well-being of their children is inspirational, assessment available at http:t.ly/ROZy

\section{REFERENCES}

I. Mathye D, Eksteen CA. Causes of childhood disabilities in a rural South African community: Caregivers' perspective. African Journal for Physical Activity and Health Sciences. 2016;22(2:2):590-604.

2. Oskoui M, Coutinho F, Dykeman J, Jetté N, Pringsheim T. An update on the prevalence of cerebral palsy: A systematic review and meta-analysis. Developmental Medicine and Child Neurology. 2013;55(6):509-519. doi: https://doi.org//0.1 I I I/dmcn. 12080

3. Couper J. Prevalence of childhood disability in rural KwaZuluNatal. South African medical journal = Suid-Afrikaanse tydskrif vir geneeskunde. 2002.

4. Couper J. Disability in Rural Kwazulu-Natal. South African Medical Journal. 2002;92(7):549-552.

5. Gunel MK, Mutlu A, Tarsuslu T, Livanelioglu A. Relationship among the Manual Ability Classification System (MACS), the Gross Motor Function Classification System (GMFCS), and the functional status (WeeFIM) in children with spastic cerebral palsy. European Journal of Pediatrics. 2009; I68(4):477-485.

doi:https://doi.org/10.1007/s0043 I-008-0775- I

6. Klutse K, Naab F. Caregivers Burden as Risk Factor against Quality of Life of Caregivers of Cerebral Palsy Patients: Moderating Role of Social Support. International Neuropsychiatric Disease Journal. 2018; I0(4): I-8. doi:https://doi.org/10.9734/indj/2017/39050

7. Abdel Malek S, Rosenbaum P, Gorter JW. Perspectives on cerebral palsy in Africa: Exploring the literature through the lens of the International Classification of Functioning, Disability and Health. Child: Care, Health and Development. 2020;46(2): I75-186. doi:https://doi.org/10.1 I I I/cch. 12733

8. Burg J. Development of a Self Care Inventory for Children With Cerebral Palsy Living in Poorly Resourced Contexts. University of Witwatersrand; 2016. https://wiredspace.wits.ac.za/bitstream/ handle/ I0539/2 I 205/Julia\%20Burg\%2002 I 5383A\%20DEVELOPMENT\%20OF\%20A\%20SELF\%20CARE\%2OINVENTORY\%20 FOR\%20CHILDREN\%20WITH\%20CEREBRAL\%20PALSY\%20 \%20.pdf?isAllowed $=y \&$ sequence $=$ I

9. Glover TA, Albers CA. Considerations for evaluating universal screening assessments. Journal of School Psychology. 2007;45(2): I 17-135. doi:https://doi.org/10.1016/j.jsp.2006.05.005

10. Pashmdarfard M, Amini M, Hassani Mehraban A. Participation of Iranian cerebral palsy children in life areas: A systematic review article. Iranian Journal of Child Neurology. 2017;1 I (I):I-12. doi:https://doi.org/I0.22037/ijcn.vl lil.I I 76 I

II. Bakuwa TC, Pilusa S, Saloojee G. The value of a short practical training course for newly qualified therapists working with children with cerebral palsy in South Africa. African Journal of Disability. 2020;9:1-12. doi:https://doi.org/10.4102/ajod.v9i0.610

12. Anaby D, Korner-Bitensky N, Steven E, Tremblay S, Snider L, Avery L, Law M. Current Rehabilitation Practices for Children with Cerebral Palsy: Focus and Gaps. Physical and Occupational Therapy in Pediatrics. 2017;37(I):I-15. doi:https://doi.org/10.3109/019426 38.2015.1126880

13. Snow C, Beals DE. Mealtime talk that supports literacy development. New Directions for Child and Adolescent Development. 2007;(I I5):83-97. doi: https://doi.org/10.1002/cd.155

14. Paulson A, Vargus-adams J. Overview of Four Functional Classification Systems Commonly Used in Cerebral Palsy. Children. 2017;4(4):30. doi:https://doi.org/10.3390/children4040030

15. Donald KA, Samia P, Kakooza-Mwesige A, Bearden D. Pediatric cerebral palsy in Africa: A systematic review. Seminars in Pediatric Neurology. 20I4;2I(I):30-35. doi:https://doi.org/10.1016/j.spen.2014.01.001

16. Matafwali B, Serpell R. Design and Validation of Assessment Tests for Young Children in Zambia. New Directions for Child and Adolescent Development. 2014;146(2014):77-96. doi:https://doi.org/10.1002/cad.20074

17. Geisinger KF. Cross-cultural normative assessment: Translation and adaptation issues influencing the normative interpretation of assess- 
ment instruments. Psychological Assessment. 1994;6(4):304-312. doi:https://doi.org/I0.1037/1040-3590.6.4.304

18. Phaswana-Mafuya N. Safe Hygiene Practices in a Rural Municipality of the Eastern Cape, South Africa. In: Olsson FM, editor. New Developments in the Psychology of Motivation. Hauppauge: Nova Science Publisher; 2008. p. 25-43.

19. Marutlulle NK. Causes of informal settlements in Ekurhuleni Metropolitan Municipality: An exploration. Africa's Public Service Delivery \& Performance Review. 2017;5(I):I-II. doi:https://doi.org/I0.4102/apsdpr.v5il.I3I

20. Anthoine E, Moret L, Regnault A, Sbille V, Hardouin JB. Sample size used to validate a scale: A review of publications on newly-developed patient reported outcomes measures. Health and Quality of Life Outcomes. 2014;/2(1):I-10. doi:https://doi.org//0.1 I86/s |2955014-0176-2

21. Bryman A. Social Research Methods. Fourth edi. Oxford University Press; 2012.

22. Deeks JJ, Altman DG. Statistics notes - Diagnostic tests 4: Likelihood ratios. British Medical Journal. 2004;329(7458): 168-169. doi:https://doi.org/I0.I I36/bmj.329.7458.168

23. Pauw K, Mncube L. Expanding the Social Security Net in South Africa: Opportunities, Challenges and Constraints. 2011. doi:https://doi.org/10.2139/ssrn. 1018900

24. Lagunju IA, Fatunde OJ. The child with cerebral palsy in a developing country - Diagnosis and beyond. Journal of Pediatric Neurology. 2009;7(4):375-379. doi:https://doi.org/10.3233/JPN-2009-0334

25. South African SDI Alliance. Gxagxa Informal Settlement Pocket \& New Rest Infill Enumeration Report. Cape Town; 2016.

https://www.westerncape.gov.za/sites/www.westerncape.gov.za/ files/hs-enumeration-study-wcg-ep-gxagxa-final.pdf

26. Parikh P, Bisaga I, Loggia C, Georgiadou MC, Ojo-Aromokudu J. Barriers and opportunities for participatory environmental upgrading: Case study of Havelock informal settlement, Durban. City and Environment Interactions. 2020;5(3): 10004I. h2. doi:https://doi.org/10.1016/j.cacint.2020.10004 I

27. Gutura P, Tanga PT. 'Income for the Whole Family': Exploring the Contribution of Social Grants to Rural Household Income in Ngqushwa Municipality, Eastern Cape Province of South Africa. Journal of Social Sciences. 2017;50(I-3): I72-I8I. doi:https://doi.org/10.1080/09718923.2017.1311733

28. Öhrvall AM, Eliasson AC, Löwing K, Ödman P, Krumlinde-Sundholm L. Self-care and mobility skills in children with cerebral palsy, related to their manual ability and gross motor function classifications. Developmental Medicine and Child Neurology. 20 10;52 (I I): 1048 1055. doi:https://doi.org/10.I I I I/j. I469-8749.2010.03764.x

29. Kim K, Kang JY, Jang DH. Relationship between mobility and selfcare activity in children with cerebral palsy. Annals of Rehabilitation Medicine. 20I7;4I(2):266-272.

doi:https://doi.org/10.5535/arm.2017.41.2.266

30. Parkes J, McCullough N, Madden A. To what extent do children with cerebral palsy participate in everyday life situations? Health \& Social Care in the Community. 2010;18(3):304-315. doi:https://doi.org/10.1 I I I/j.1365-2524.2009.00908.x

31. Chien CW, Brown T, Mcdonald R, Yu ML. The contributing role of real-life hand skill performance in self-care function of children with and without disabilities. Child: Care, Health and Development. 2014;40(I): I34-144. doi:https://doi.org/10.1 I I /j.1365-2214.2012.01429.x

32. Trevethan R. Sensitivity, Specificity, and Predictive Values: Foundations, Pliabilities, and Pitfalls in Research and Practice. Frontiers in Public Health. 2017;5:307. 00307/full. doi:https://doi.org/10.3389/fpubh.2017.00307

33. Bagley AM, Gorton G, Oeffinger D, Barnes D, Calmes J, Nicholson D, Damiano D, Abel M, Kryscio R, Rogers S, et al. Outcome assessments in children with cerebral palsy, Part II: Discriminatory ability of outcome tools. Developmental Medicine and Child Neurology. 2007;49(3):|181-186.

doi:https://doi.org/I0.1 I I I/j. I469-8749.2007.00I8I.x

34. Davies PL, Soon L, Young M, Clausen-Yamaki A. Validity and Reliability of the School Function Assessment in Elementary School Students with Disabilities. Physical and Occupational Therapy In Pediatrics. 2004;24(3):23-43. doi: https://doi.org/10.1300/j006v24n03_03

35. Gladstone M, Lancaster GA, Umar E, Nyirenda M, Kayira E, van den Broek NR, Smyth RL. The Malawi Developmental Assessment Tool (MDAT): The Creation, Validation, and Reliability of a Tool to Assess Child Development in Rural African Settings. PLoS Medicine. 2010;7(5):el000273. doi:https://doi.org/10.1371/journal.pmed. 1000273

Corresponding Author

*Denise Franzsen

Email: Denise.Franzsen@wits.ac.za 